\title{
Dependence of ZnO Nanostructured Thin Films Properties on Growth Temperature by APCVD Method
}

\author{
M. MALEKI ${ }^{a, *}$ AND S.M. ROZATI ${ }^{b}$ \\ ${ }^{a}$ Department of Physics, Faculty of Science, Fouman and Shaft Branch, Islamic Azad University, Fouman, Iran \\ ${ }^{b}$ CVD Lab., Physics Department, University of Guilan, Namjoo St., Faculty of Science, Rasht, Iran
}

(Received January 9, 2015; in final form April 19, 2015)

In this paper, the effect of substrate temperature on the electrical, structural, morphological and optical properties of nanostructured polycrystalline zinc oxide thin films were investigated by the Hall measurement, Xray diffraction, scanning electron microscopy and UV-visible spectrophotometer, respectively. Then these modified thin films were deposited on two kinds of single crystal and polycrystalline of $n$ - and $p$-type Si in three different substrate temperatures of 300,400 and $500{ }^{\circ} \mathrm{C}$ by low cost atmospheric pressure chemical vapor deposition method. Like the samples grown on the glass substrate, with increase of the temperature in samples grown on single crystal $\mathrm{Si}$, preferred orientation changes from (100) to (002), while in samples deposited on poly crystalline Si, preferred orientation remains $(100)$.

DOI: $10.12693 /$ APhysPolA.128.367

PACS: $73.90 .+\mathrm{f}$

\section{Introduction}

$\mathrm{ZnO}$ is an $n$-type II-VI group compound with a wurtzite structure. $\mathrm{ZnO}$ films have been widely studied owing to their usefulness in electronic or optoelectronic applications, gas sensors, solar cell windows, and surface acoustic-wave devices [1-4].

Based on many reviewed articles from 1985 up to now, there are many articles in which they investigated doped $\mathrm{ZnO}$ in order to obtain the best TCO layers for solar cell applications [5-12]. The best resistivity was reported in the range of $3.4 \times 10^{-3} \Omega \mathrm{cm}$ for $\mathrm{ZnO}: \mathrm{Al}$ [7] to about $10^{-5} \Omega \mathrm{cm}$ for $\mathrm{ZnO}: \mathrm{In}$ [5], while the transparency of the layers changed in the range $80-90 \%$. Although these results are praiseworthy, there are few articles about pure $\mathrm{ZnO}$ and the effect of substrate temperature on electrical, optical, structural and morphological properties "simultaneously" with low cost atmospheric pressure chemical vapor deposition (APCVD) method.

For example, in 1999, Haga et al. produced conductive transparent $\mathrm{ZnO}$ films with the best resistivity of about $10^{-2} \Omega \mathrm{cm}$ and the transparency of about $80 \%$ [13]. They studied the effect of ozone generation rate on electrical properties of $\mathrm{ZnO}$ layers. In 2000, Takahashi et al. studied the effect of substrate temperature on growth rate of $\mathrm{ZnO}$ films with the precursors of $\mathrm{ZnCl}_{2}$ and $\mathrm{O}_{2}$ [14]. Their research was devoted to structural properties and FWHM changes with $\mathrm{O}_{2}$ and $\mathrm{ZnCl}_{2}$ pressure. In 2002, Fu et al. investigated the structure and photoluminescence (PL) at room temperature of $\mathrm{ZnO}$ films deposited on $\mathrm{Si}$ (111) substrates by metal-organic chemical vapor deposition (MOCVD) using diethylzinc (DEZ) and CO [15]. It was found that these properties strongly depend on growth temperature and pressure.

*corresponding author; e-mail: m.maleki@fshiau.ac.ir
Morphological and structural properties of $\mathrm{ZnO}$ thin films were studied by Hong et al. in 2003 [16]. They used single source chemical vapor deposition (SSCVD) under low vacuum conditions with the precursor of zinc carbamate $\mathrm{Zn}_{4} \mathrm{O}\left(\mathrm{CO}_{2} \mathrm{Net}_{2}\right)_{6}$. Careful quantitative XPS analysis revealed that the $\mathrm{ZnO}$ films were stoichiometric with $\mathrm{O} / \mathrm{Zn}$ atomic ratio very close to that of $\mathrm{ZnO}$ single crystal. In 2005, Kopalko et al. reported that monocrystalline films were obtained only for $\mathrm{GaN} / \mathrm{Al}_{2} \mathrm{O}_{3}$ substrates, whereas use of sapphire, silicon or soda lime glass resulted in either 3D growth mode or in polycrystalline films showing preferential orientation along the $c$ axis [17]. In 2006, Romero et al. studied the effect of kind of precursor on structural properties of $\mathrm{ZnO}$ thin films [18]. They concluded that the preferred orientation can be altered by changing the deposition conditions: the substrate temperature, the precursor solution composition or by introducing aluminum. In 2007, growth of $\mathrm{ZnO}$ films and nanowires (NWs) by atmospheric pressure chemical vapor deposition (APCVD) using Zn powder and water as source materials were performed [19].

Photoluminescence intensity ratio of the green band at about $2.5 \mathrm{eV}$ to the near-band-edge emission at about $3.2 \mathrm{eV}$ decreased with increase of the source feeding ratio of $\mathrm{H}_{2} \mathrm{O}$ to $\mathrm{Zn}$ (VI/II), indicating the possibility of the defect control. In $2008, \mathrm{ZnO}$ thin films were prepared using zinc chloride, zinc acetate and zinc nitrate precursors by spray pyrolysis technique on glass substrates at $550{ }^{\circ} \mathrm{C}[20]$. Regardless of precursors, $\mathrm{ZnO}$ thin films were all in hexagonal crystallographic phase and had (002) preferred orientation. Scanning electron microscopy (SEM) images showed completely different surface morphologies for each precursor in $\mathrm{ZnO}$ thin films. $\mathrm{ZnO}$ rod was observed only for zinc chloride precursor. The optical measurements revealed that films had a low transmittance and a direct band gap approximately $3.30 \mathrm{eV}$. In 2009, $\mathrm{ZnO}$ thin films synthesized by chemical bath deposition were used as buffer layer 
between the anode and the organic electron donor in organic solar cells [21]. In 2010, $\mathrm{ZnO}$ thin films were grown on glass substrate by APCVD, using zinc acetate as precursor of $\mathrm{Zn}$ and ozone as an oxidant agent [22]. The structural and optical properties of $\mathrm{ZnO}$ films were investigated in different deposition temperatures (300$375^{\circ} \mathrm{C}$ in steps of $25^{\circ} \mathrm{C}$ ). All deposited films were polycrystalline in (100) preferred orientation and had transparency of about $80 \%$ in the visible region. In 2011, zinc oxide thin films were deposited on glass substrates from room temperature to $673 \mathrm{~K}$ by using DC magnetron sputtering [23]. The preferred orientation for $\mathrm{ZnO}$ thin films lies along (002) direction and the average crystallite size was determined from the Scherrer formula. SEM images showed that grain sizes of zinc oxide thin films was found to be in the range of $15-28 \mathrm{~nm}$.

In 2012, it was shown that variations in the ratio of oxygen to zinc precursors at constant temperature allow changing the surface morphology of zinc oxide $(\mathrm{ZnO})$ films deposited by low pressure MOCVD, while keeping the sheet resistance and transparency of the layers constant [24].

In 2014, boron doped zinc oxide films were prepared at different water to diethyl zinc ratios by a low pressure CVD technique [25]. It was found that the morphology of the films vary from small leaf like to pyramidal surface structures with increase of $\mathrm{H}_{2} \mathrm{O} / \mathrm{DEZ}$ flow ratio.

Therefore, in this paper we want to investigate the effect of deposition temperature on electrical, optical, structural and morphological properties of pure $\mathrm{ZnO}$ thin films by the Hall effect and Van der Pauw setup, UV-visible spectrophotometer, X-ray diffractometer and SEM measurement. Also, in order to study the importance of the kind of the substrate on modifying structural properties, we used two types of Si substrate.

\section{Experimental techniques}

\subsection{Sample preparation}

The glass substrates were degreased as described in our previous work [26]. We have used oxygen gas with purification of 99.999 (contained: maximally 2 ppm argon, 5 ppm nitrogen, 0.5 ppm hydrogen, $0.5 \mathrm{ppm} \mathrm{CO}+\mathrm{CO}_{2}$, $0.5 \mathrm{ppm}$ methane + hydrocarbons and $1 \mathrm{ppm}$ water) and zinc acetate $\left(\mathrm{C}_{4} \mathrm{H}_{6} \mathrm{O}_{4} \mathrm{Zn} \cdot 2 \mathrm{H}_{2} \mathrm{O}\right)$ as precursors. The mass of zinc acetate was $0.2 \mathrm{~g}$ in all experiments and we introduced it as powder directly in the reactor with a distance about $5 \mathrm{~cm}$ from the substrate. Deposition was carried out in a homemade APCVD described in our previous study [27]. Oxygen flow rate was kept at $200^{\circ} \mathrm{C} / \mathrm{min}$, substrate temperature was changed in the range $300-500^{\circ} \mathrm{C}$ and layers were deposited during $1 \mathrm{~h}$.

$\mathrm{ZnO}$ films were deposited onto silicon substrates in an open tube system by the oxidation of $\mathrm{C}_{4} \mathrm{H}_{6} \mathrm{O}_{4} \mathrm{Zn} \cdot 2 \mathrm{H}_{2} \mathrm{O}$. Before deposition, the silicon substrates were degreased about $2 \mathrm{~min}$ in solution of hydro fluoric acid and deionised water then rinsed in deionised water. These silicones were cleaned ultrasonically in acetone and rinsed again in deionised water. The cleaned Si substrates were introduced in the tubular furnace. The thickness of two types of Si were 650 and $750 \mu \mathrm{m}$; their resistivity were $3.51 \times 10^{2} \Omega \mathrm{cm}, 4.95 \times 10^{2} \Omega \mathrm{cm}$; their mobility were $207,822\left(\mathrm{~cm}^{2} /(\mathrm{V} \mathrm{s})\right)$ and their carrier concentration were $2.44 \times 10^{14}, 4.63 \times 10^{12} \mathrm{~cm}^{-3}$ for polycrystalline and single crystal Si, respectively. Polycrystalline Si was $p$-type with B doped, while single crystal Si was $n$-type with $\mathrm{P}$ doped. Single crystal silicon's orientation is (400). Our samples were grown at an oxygen flow rate of $200 \mathrm{sccm}$ in substrate temperature of 300,400 and $500^{\circ} \mathrm{C}$ during $1 \mathrm{~h}$.

\subsection{Sample characterization}

The electrical properties of thin films were measured by the Hall effect and Van der Pauw setup (RH 2010 - PhysTech system). A UV-visible spectrophotometer (Cary 100 Scan Varian) was employed for obtaining transmittance spectra. A spectrophotometric transmittance graph of the film was used for the thickness calculation by the Swanepoel method [28]. The crystalline structure was obtained by means of an X-ray diffractometer with $\mathrm{Cu} K_{\alpha}$ radiation (Philips-pw-1830). The morphology of the surface of films was examined by scanning electron microscopy (EM-3200,KYKY).

\section{Results and discussion}

\subsection{Electrical properties}

Figure 1 shows changes of sheet resistance versus deposition temperature. With increase of substrate temperature from $300^{\circ} \mathrm{C}$, sheet resistance increases and after a maximum at $450^{\circ} \mathrm{C}$ it decreases. For more investigation, from Fig. 2, which presents changes of electrical parameters such as resistivity, carrier concentration and mobility versus deposition temperature, it can be deduced that this figure is in accordance with sheet resistance diagram.



Fig. 1. Changes of sheet resistance versus deposition temperature.

As shown in Fig. 2, with increase of substrate temperature, resistivity increases and after reaching a 




Fig. 2. Changes of electrical parameters such as resistivity, carrier concentration and mobility versus deposition temperature.

maximum, it decreases. While mobility does not show clear change up to $450^{\circ} \mathrm{C}$ and with more increase of substrate temperature, it suddenly increases severely. We can relate this suddenly increase of mobility with decrease of carrier concentration scattering as a result of carrier decreasing. Also, mobility improves due to grain size increase which will be discussed in the following. As a result of this suddenly increase of mobility, resistivity decreases. With respect to the diagram, it is clear that carrier concentration decreases with increasing temperature. It is reasoned that when the substrate temperature is increased, the number of oxygen atoms adsorbed on the thin films will be increased, causing a decrease of the defect density and resulting in a decrease of the carrier concentration [29]. These results imply that as the substrate temperature is increased from 300 to $450{ }^{\circ} \mathrm{C}$, the thin films come closer to the stoichiometrical composition. Our results are in good agreement with Kang et al. report in which they used pulsed laser deposition method with different precursors [30].

TABLE

Values of electrical parameters of the samples for various substrate temperatures. Type of doping — $n$ (for all temperatures).

\begin{tabular}{|c|c|c|c|c|c|c|c|}
\hline $\begin{array}{c}\text { Temperature } \\
{\left[{ }^{\circ} \mathrm{C}\right]}\end{array}$ & $\begin{array}{c}\text { Thickness } \\
\text { [nm] }\end{array}$ & $\begin{array}{c}\text { Sheet } \\
\text { resistance } \\
{[\Omega / \square]}\end{array}$ & $\begin{array}{c}\text { Resistivity } \\
{[\Omega \mathrm{cm}]}\end{array}$ & $\begin{array}{l}\text { Hall co. } \\
{\left[\mathrm{cm}^{3} / \mathrm{As}\right]}\end{array}$ & $\begin{array}{l}\text { Mobility } \\
{\left[\mathrm{cm}^{2} / \mathrm{Vs}\right]}\end{array}$ & $\begin{array}{c}\text { Carrier } \\
\text { concentration } \\
{\left[\mathrm{cm}^{-3}\right]}\end{array}$ & Type \\
\hline 300 & 508 & $6.14 \times 10^{6}$ & $3.12 \times 10^{2}$ & $-3.96 \times 10^{2}$ & 1.27 & $1.57 \times 10^{16}$ & $n$ \\
\hline 350 & 608 & $8.98 \times 10^{6}$ & $5.46 \times 10^{2}$ & $-2.56 \times 10^{2}$ & 0.5 & $2.44 \times 10^{16}$ & $n$ \\
\hline 400 & 526 & $3.99 \times 10^{7}$ & $2.1 \times 10^{3}$ & $-1.4 \times 10^{3}$ & 0.5 & $5.98 \times 10^{15}$ & $n$ \\
\hline 450 & 474 & $1.15 \times 10^{8}$ & $5.47 \times 10^{3}$ & $-1.88 \times 10^{3}$ & 0.3 & $3.32 \times 10^{15}$ & $n$ \\
\hline 500 & 487 & $2.71 \times 10^{7}$ & $1.32 \times 10^{3}$ & $-1.32 \times 10^{3}$ & 99 & $4.74 \times 10^{14}$ & $n$ \\
\hline
\end{tabular}

Table shows changes of thickness, sheet resistance, resistivity, Hall coefficient, mobility, carrier concentration and the type of carrier versus deposition temperature.

\subsection{Structural and morphological properties}

Figure 3 shows typical XRD patterns of the $\mathrm{ZnO}$ layers grown on glass substrate at different deposition temperature. All films have polycrystalline structure with a hexagonal wurtzite structure. Although the peaks intensity is so weak at low deposition temperature, with increase of temperature it increases. This is due to the low atomic mobility, which constrains the growth of the crystal during the crystallization process at low temperatures. As the substrate temperature increases up to $500^{\circ} \mathrm{C}$, enough thermal energy is supplied to the adatoms on the substrate and increases the surface mobility leading to an increase in the (002) plane orientation [30].

At substrate temperature of 300 and $400^{\circ} \mathrm{C}$, preferred orientation is (100) while at $500{ }^{\circ} \mathrm{C}$ it changes to (002). The primary effect of a change in composition from an oxygen-deficient material to stoichiometric $\mathrm{ZnO}$ is a preferred (002) orientation [31, 32]. With increasing substrate temperature, $\mathrm{ZnO}$ layers approach to a stoichiometric ones and preferred orientation changes to (002) peak.

Since amount of the oxygen incorporation into lattices may increase at higher substrate temperature [33]. Also, the thermal energy of the substrate can supply enough energy necessary to form the (002) orientation. As a result, the films prepared at the higher temperature show a good crystalline quality [33].

As depicted in Fig. 4, the increase of grain size as a result of temperature increase is clear. The mean crystallite size $D$ was calculated for the diffraction peaks using the Scherrer formula [34]. Grain size was calculated for (002) orientation. This demonstrated that the crystallinity of $\mathrm{ZnO}$ films was likely to improve with increase of deposition temperature. Although some others used different precursors and other deposition methods, our results are in good agreement with theirs $[10,35]$.

Figure 5 shows typical XRD patterns of the $\mathrm{ZnO}$ layers grown on single and polycrystalline $\mathrm{Si}$ at three substrate temperatures of 300,400 and $500^{\circ} \mathrm{C}$. It is worth noticing this fact that samples which have been grown at all substrate temperatures have polycrystalline structure. Like 




Fig. 3. XRD patterns of the $\mathrm{ZnO}$ layers grown on glass substrate at different deposition temperature.



Fig. 4. Changes of grain size as a result of temperature increase.
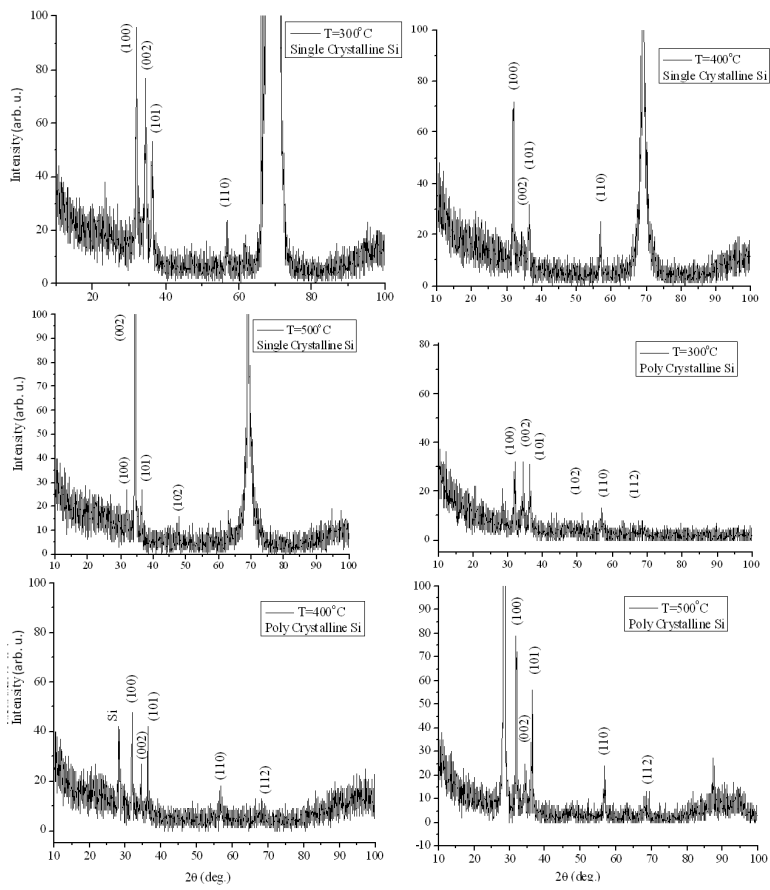

Fig. 5. XRD patterns of the $\mathrm{ZnO}$ layers grown on single and polycrystalline $\mathrm{Si}$ at three substrate temperatures of 300,400 and $500{ }^{\circ} \mathrm{C}$. the samples grown on the glass substrate, with increase of the temperature in samples grown on single crystal Si, preferred orientation changes from (100) to (002), while in samples deposited on poly crystalline $\mathrm{Si}$, preferred orientation remains (100). The surface energy of the (002) orientation takes minimum in the $\mathrm{ZnO}$ crystal, and then in order to grow a $c$-axis oriented $\mathrm{ZnO}$ crystal, it is important that the particles ablated from the target have still energy at the substrate surface [33]. It seems that in the case of $\mathrm{ZnO}$ layers on polycrystalline $\mathrm{Si}$, particles do not have enough energy to form $\mathrm{ZnO}$ layers with (002) preferred orientation. We can relate this phenomenon to the type of the polycrystalline Si. Indeed, (100) preferred orientation in this case can be formed due to the presence of the residual stress in the film that depends on experimental conditions and substrate nature.

As expected in both cases, with increasing temperature, the intensity of the preferred peak increases due to improving crystallinity. The effect of Si substrate is clear with its peak at about $70^{\circ}$ for single crystal Si and at $28^{\circ}$ for polycrystalline Si.

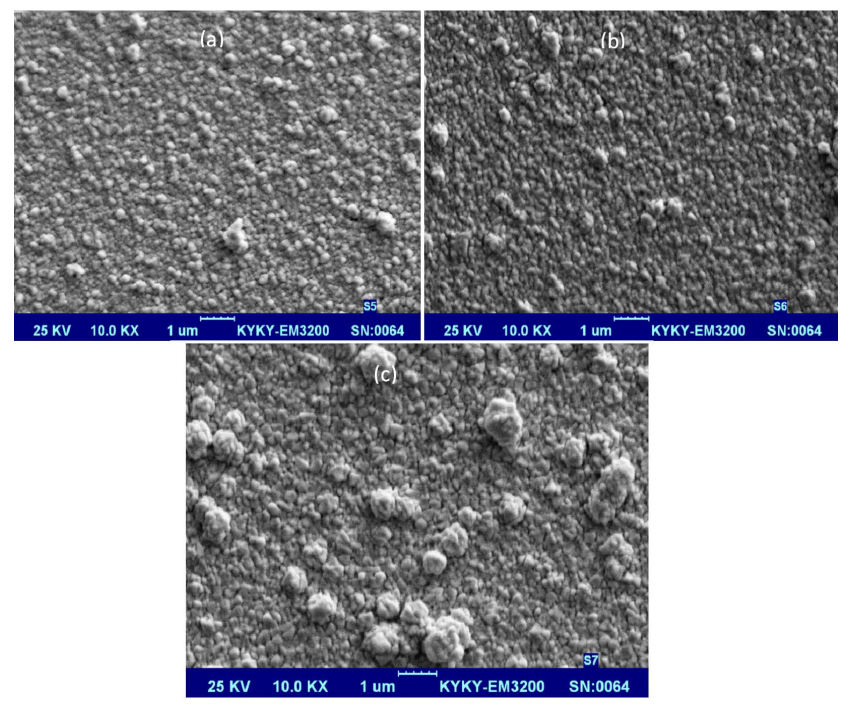

Fig. 6. SEM images of the $\mathrm{ZnO}$ thin films deposited at various glass substrate temperatures.

Figure 6 shows SEM images of the $\mathrm{ZnO}$ thin films deposited at various glass substrate temperatures. All of the thin films show nanometer-sized grains and a dense microstructure. In the case of the thin films deposited at $300^{\circ} \mathrm{C}$, small grains were observed. As the substrate temperature is increased up to $500^{\circ} \mathrm{C}$, the surface morphology is observed to consist of larger and more packed grains.

\subsection{Optical properties}

Figure 7 shows transmission spectra of $\mathrm{ZnO}$ thin films at different substrate temperatures. All layers have acceptable transmission for solar cell applications. As it is clear, transparency does not have distinct change due to low carrier concentration of the samples. As a result, 
absorption of free carrier concentration is low and transparency is high. These results are in accordance with Fay et al. report [36].

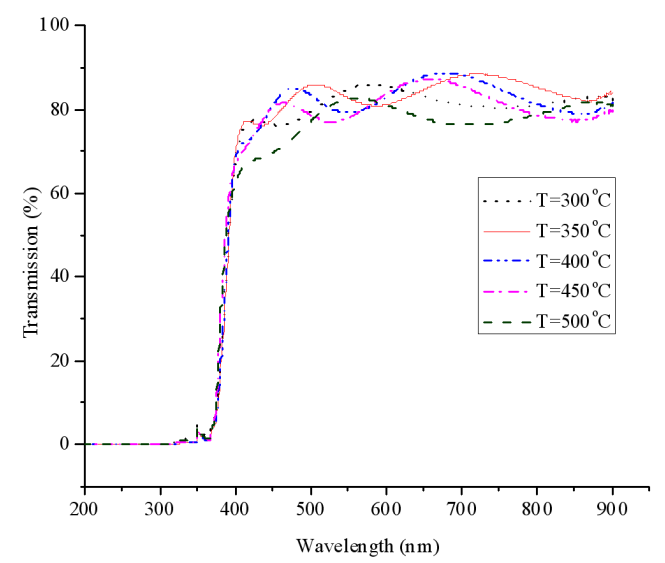

Fig. 7. Transmission spectra of $\mathrm{ZnO}$ thin films at different substrate temperatures.

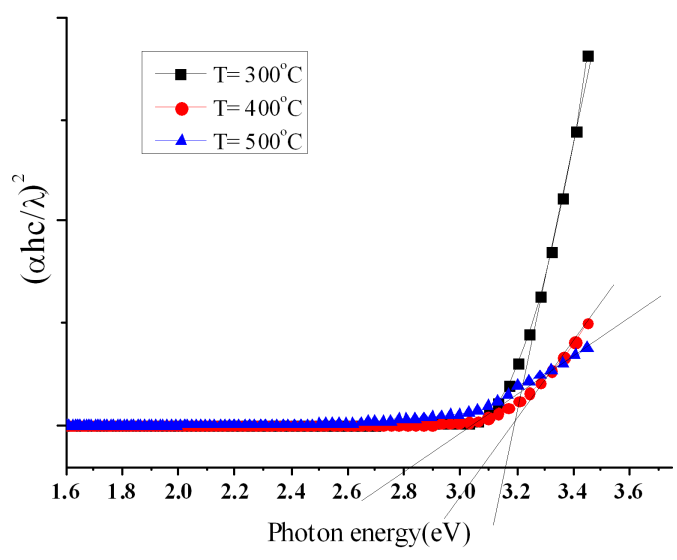

Fig. 8. Optical band gap of $\mathrm{ZnO}$ thin films at substrate temperature of $300,400,500{ }^{\circ} \mathrm{C}$.

The optical band gap, $E_{\mathrm{g}}$ of the $\mathrm{ZnO}$ thin films was determined by extrapolation of the linear portion of $(\alpha h \nu)^{2}$ versus $h \nu$ plots by applying the Tauc model which is clear in Fig. 8 [37].

As the growth temperature was reduced from 500 to $300^{\circ} \mathrm{C}$, the optical band gap blueshifted from 2.8 to $3.2 \mathrm{eV}$. A similar blueshift phenomenon of optical band gap was also observed in $\mathrm{ZnO}$ thin films deposited on quartz substrate [38]. Decrease of band gap as a result of increase of substrate temperature can be explained by the composition variation as a function of the growth temperature [39].

\section{Conclusions}

According to this paper, we studied the effect of deposition temperature on optoelectrical, structural and morphological properties of $\mathrm{ZnO}$ thin films. From the Hall measurement, resistivity increased with substrate temperature, as a result of increase of the number of oxygen atoms adsorbed on the thin films, causing a decrease of the defect density and resulting in a decrease of the carrier concentration. In accordance with electrical properties, structural properties of both layers grown on glass substrate and Si substrate improved due to deposition temperature increase and these results were approved by SEM images. As the substrate temperature increased enough thermal energy was supplied to the adatoms on the substrate and increased the surface mobility leading to an increase in the (002) plane orientation. Also, as a result of increasing crystallinity, transparency improved. Finally, transparency and band gap was acceptable for thin film $\mathrm{ZnO}$ while electrical properties should be modified by other factors such as doping, etc.

\section{Acknowledgments}

This project was supported by the Islamic Azad University, Fouman and Shaft branch, Iran and performed in the Physics Department of the University of Guilan.

\section{References}

[1] M. Pacio, H. Juarez, G. Escalante, G. Garcia, T. Diaz, E. Rosendo, Mater. Sci. Eng. B 174, 38 (2010).

[2] P. Nunes, E. Fortunato, R. Martins, Mater. Res. Soc. Symp. Proc. 666, 1 (2001).

[3] A.A. Ibrahim, A. Ashour, J. Mater. Sci. Mater. Electron. 17, 835 (2006).

[4] S. Wu, R. Ro, Z.X. Lin, Appl. Phys. Lett. 94, 1 (2009).

[5] S. Major, A. Banerjee, K.L. Chopra, Thin Solid Film 125, 179 (1985).

[6] J. Hu, R.G. Gordon, Solar Cells 30, 437 (1991).

[7] T. Minami, H. Sato, H. Sonohara, S. Takata, T. Miyata, I. Fukuda, Thin Solid Films 253, 14 (1994).

[8] B.M. Ataev, A.M. Bagamadova, V.V. Mamedov, A.K. Omaev, Mater. Sci. Eng. B 65, 159 (1999).

[9] B.K. Meyer, J. Sann, D.M. Hofmann, C. Neumann, A. Zeuner, Semicond. Sci. Technol. 20, S62 (2005).

[10] S.M. Park, T. Ikegami, K. Ebihara, Thin Solid Films 513, 90 (2006).

[11] J.G. Lu, T. Kawaharamura, H. Nishinaka, Y. Kamada, T. Ohshima, S. Fujita, J. Cryst. Growth $\mathbf{2 9 9}$, 1 (2007).

[12] C.F. Yu, S.H. Chen, S.J. Sun, H. Chou, J. Phys. D Appl. Phys. 42, 035001 (2009).

[13] K. Haga, F. Katahira, H. Watanabe, Thin Solid Films 343-344, 145 (1999).

[14] N. Takahashi, K. Kaiya, K. Omichi, T. Nakamura, S. Okamoto, H. Yamamoto, J. Cryst. Growth 209, $822(2000)$.

[15] Z. Fu, B. Lin, J. Zu, Thin Solid Films 402, 302 (2002).

[16] D. Hong, B. Gong, A.J. Petrella, J.J. Russell, R.N. Lamb, Sci. China (Series E) 46, 355 (2003). 
[17] K. Kopalko, A. Wójcik, M. Godlewski, E. Łusakowska, W. Paszkowicz, J.Z. Domagała, M.M. Godlewski, A. Szczerbakow, K. Świątek, K. Dybko, Phys. Status Solidi C 2, 1125 (2005).

[18] R. Romero, D. Leinen, E.A. Dalchiele, J.R. RamosBarrado, F. Martin, Thin Solid Films 515, 1942 (2006).

[19] T. Terasako, M. Yagi, M. Ishizaki, Y. Senda, H. Matsuura, S. Shirakata, Thin Solid Films 516, 159 (2007).

[20] E. Bacaksiz, M. Parlak, M. Tomakin, A. Ozcelik, M. Karakız, M. Altunbas, J. Alloys Comp. 466, 447 (2008).

[21] Y. Lare, A. Godoy, L. Cattin, K. Jondo, T. Abachi, F.R. Diaz, M. Morsli, K. Napo, M.A. del Valle, J.C. Bernede, Appl. Surf. Sci. 255, 6615 (2009).

[22] M. Pacio, H. Juarez, G. Escalante, G. Garcia, T. Diaz, E. Rosendo, Mater. Sci. Eng. B 174, 38 (2010).

[23] B. Rajesh Kumar, T. Subba Rao, Digest J. Nanomater. Biostruct. 6, 1281 (2011).

[24] S. Nicolay, M. Benkhaira, L. Ding, J. Escarre, G. Bugnon, F. Meillaud, C. Ballif, Solar Energy Mater. Solar Cells 105, 46 (2012).

[25] M. Wan, H. Zhu, Y. Wang, J. Yin, J. Gao, Z. Wang, F. Gun, Y. Mai, Y. Huang, W. Yu, S. Huang, Appl. Phys. A 115, 297 (2014).

[26] M. Maleki, S.M. Rozati, Phys. Scr. 86, 015801 (2012).

[27] M. Maleki, S.M. Rozati, Bull. Mater. Sci. 36, 217 (2013).
[28] R. Swanepoel, J. Phys. E Sci. Instrum. 16, 1214 (1983).

[29] N. Srinivasa Murty, S.R. Jawalekar, Thin Solid Films 102, 283 (1983).

[30] S.J. Kang, Y.H. Joung, H.H. Shin, Y.S. Yoon, J. Mater. Sci. Mater. Electron. 19, 1073 (2008).

[31] K.H. Yoon, J.W. Choi, D.H. Lee, Thin Solid Films 302, 116 (1997).

[32] M.J. Brett, R.R. Parsons, J. Mater. Sci. 22, 3611 (1987).

[33] T. Ohshima, R.K. Thareja, T. Ikegami, K. Ebihara, Surf. Coat. Technol. 169-170, 517 (2003).

[34] B.D. Cullity, Elements of X-Ray Diffraction, Addison-Wesley, Reading 1978.

[35] G. Luka, T. Krajewski, L. Wachnicki, B. Witkowski, E. Lusakowska, W. Paszkowicz, E. Guziewicz, M. Godlewski, Phys. Status Solidi A 207, 1568 (2010).

[36] S. Fay, U. Kroll, C. Bucher, E. Vallat-Sauvain, A. Shah, Solar Energy Mater. Solar Cells 86, 385 (2005).

[37] J. Tauc, Amorphous and Liquid Semiconductors, Plenum, London 1974

[38] S.T. Tan, B.J. Chen, X.W. Sun, H.S. Kwok, W.J. Fan, X.H. Zhang, S.J. Chua, J. Appl. Phys. 98, 013505 (2005).

[39] G. Sanon, R. Rup, A. Masingh, Phys. Rev. B 44, $5672(1988)$ 